Supporting Information

\title{
Luminescent Zinc(II) Coordination Polymers of Bis(pyridin-4-yl)benzothiadiazole and Aromatic Polycarboxylates for Highly Selective Detection of Fe(III) and High \\ Valent Oxyanions
}

Qi-Jin Jiang, ${ }^{\dagger}$ Jia-Yu Lin, ${ }^{\dagger}$ Zhi-Jia Hu, ${ }^{\dagger}$ Vincent K. S. Hsiao, ${ }^{\ddagger}$ Mei-Ying Chung ${ }^{\S}$ and Jing-Yun Wu*,

${ }^{\dagger}$ Department of Applied Chemistry, National Chi Nan University, Nantou 545, Taiwan

${ }^{\ddagger}$ Department of Applied Materials and Optoelectronic Engineering, National Chi Nan University, Nantou 545, Taiwan

$\S$ Institute of Chemistry, Academia Sinica, Taipei, 115, Taiwan

Corresponding author.

E-mail address: jyunwu@ncnu.edu.tw (J.-Y. Wu) 

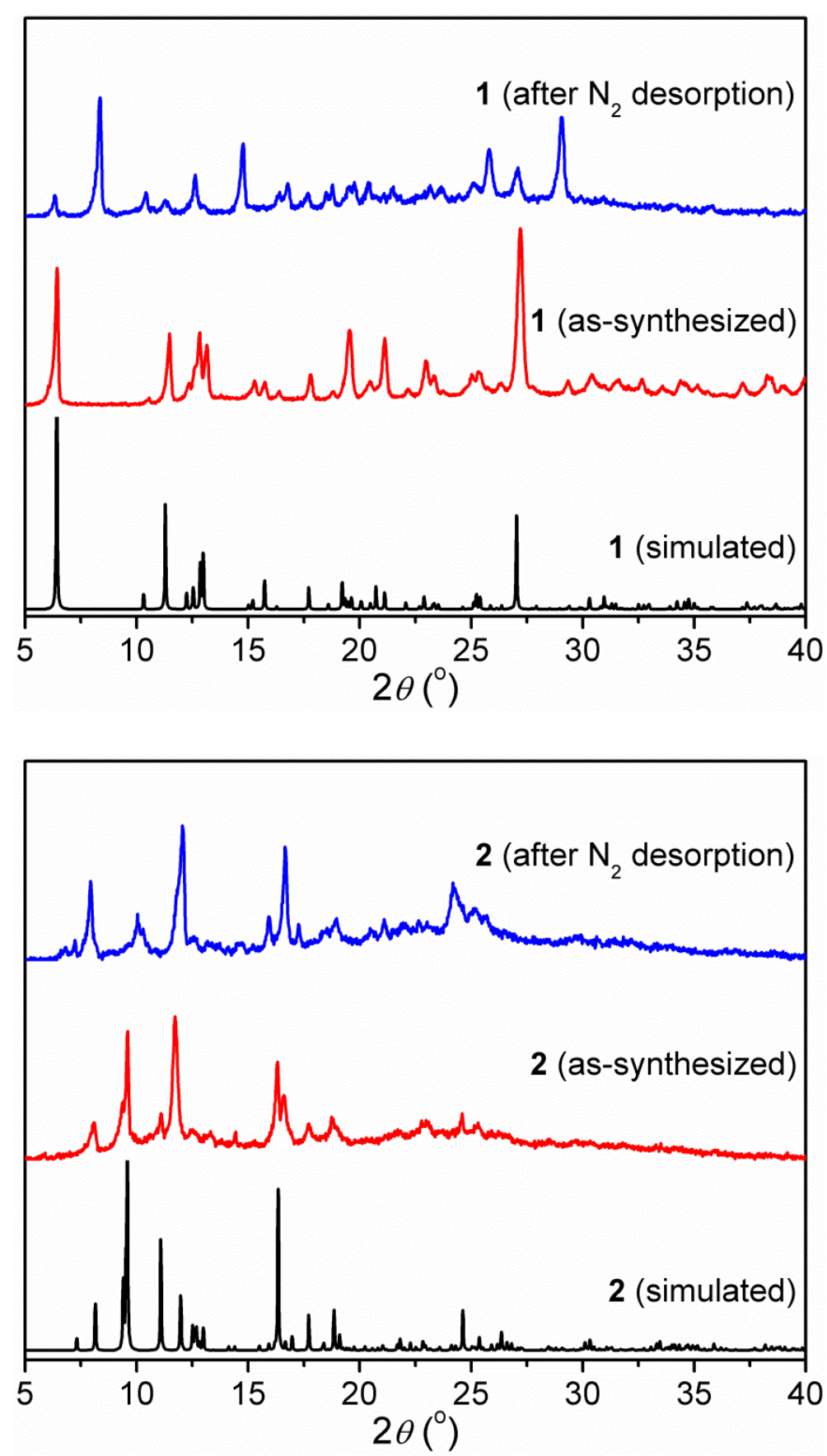

Figure S1. XRPD patterns of compounds 1 and 2: simulated, as-synthesized, and after $\mathrm{N}_{2}$ desorption. 


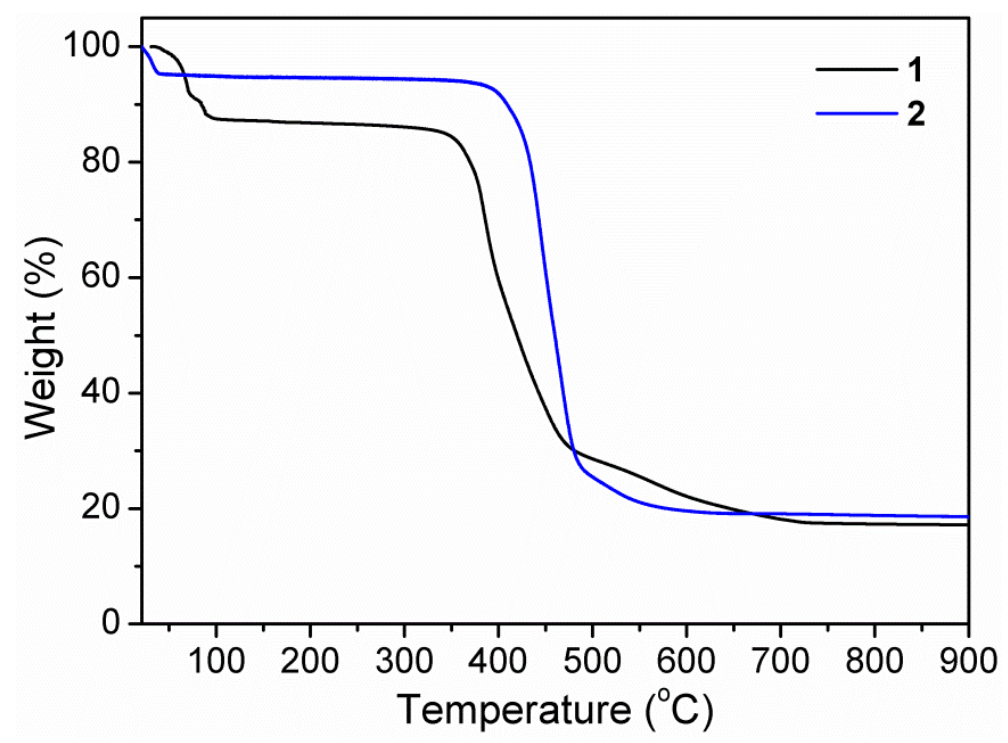

Figure S2. TGA diagrams of compounds $\mathbf{1}$ and $\mathbf{2}$.

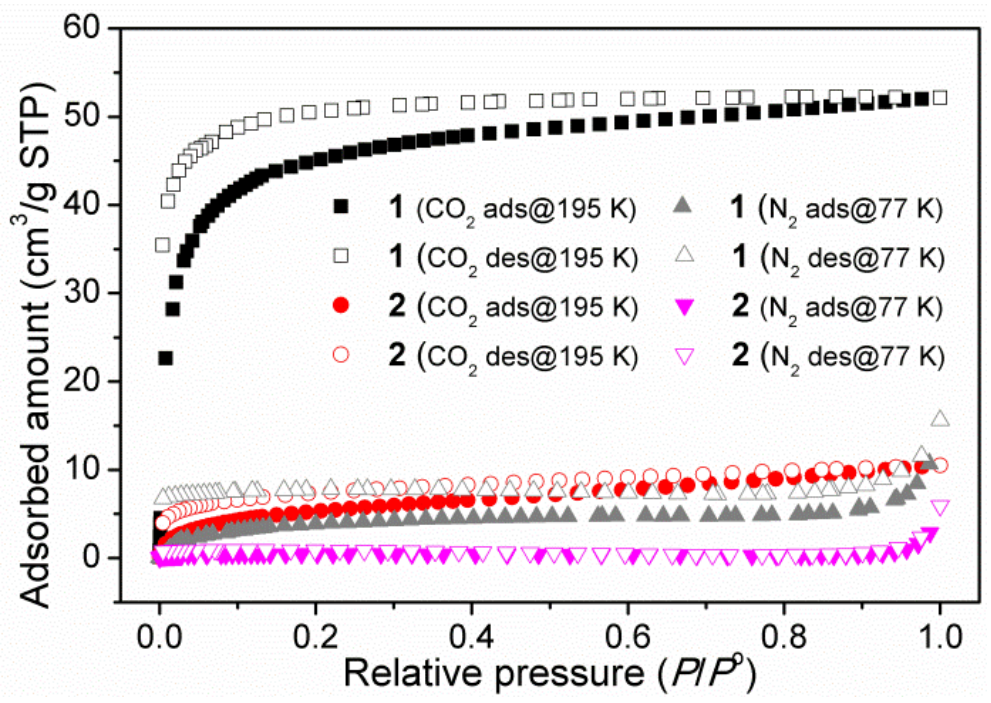

Figure S3. Gas adsorption isotherms for thermally activated $\mathbf{1}$ and $\mathbf{2}$ conducted at $77 \mathrm{~K}$ for $\mathrm{N}_{2}$ and $195 \mathrm{~K}$ for $\mathrm{CO}_{2}$. 


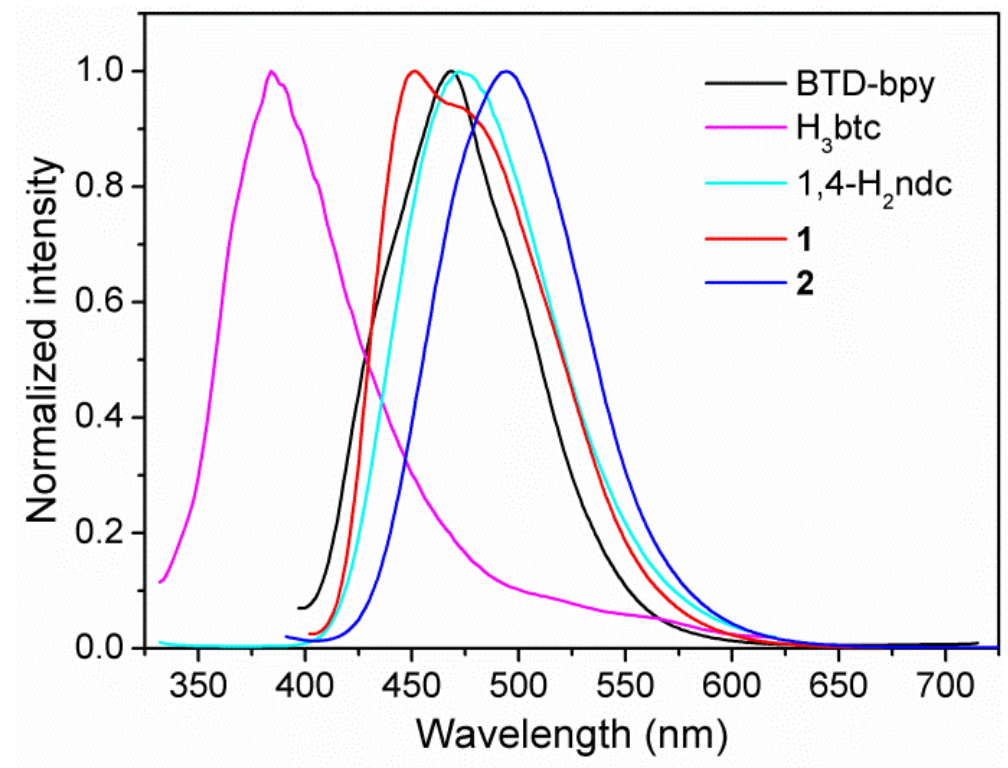

Figure S4. Normalized luminescence spectra of BTD-bpy, $\mathrm{H}_{3}$ btc, 1,4- $\mathrm{H}_{2}$ ndc, and compounds 1 and 2 in solid-state at room temperature. 

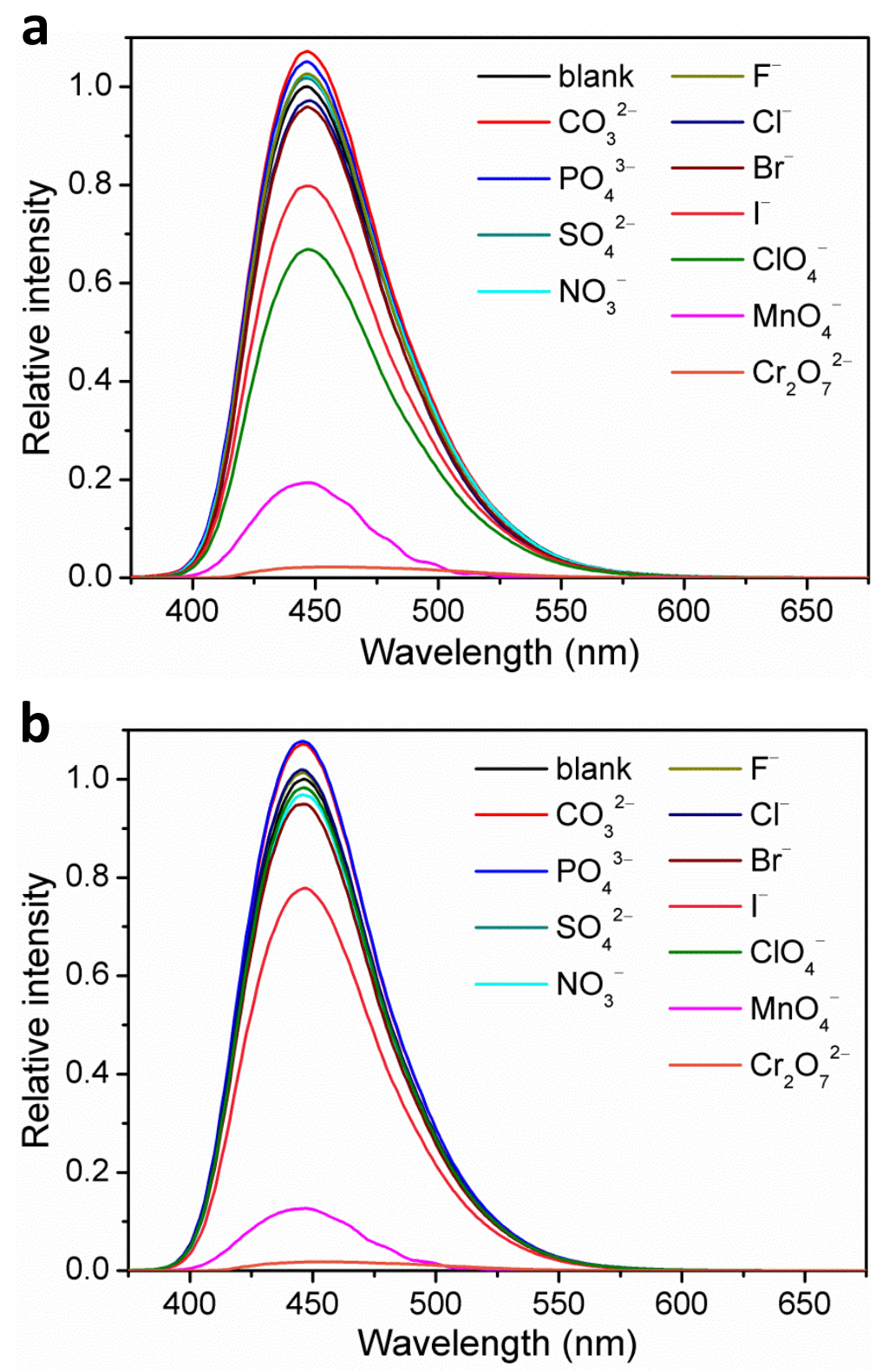

Figure S5. Emission spectra of (a) 1 and (b) $\mathbf{2}$ dispersed in DMF solvent upon addition of different anions at room temperature when excited at $360 \mathrm{~nm}$. 


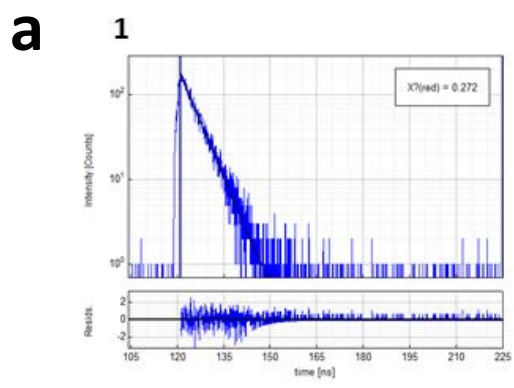

$z(i)=\sum i_{i} e^{-\frac{1}{4}}$

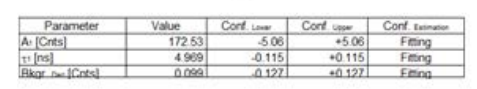

1 (after treated with $\mathrm{MnO}_{4}^{-}$)

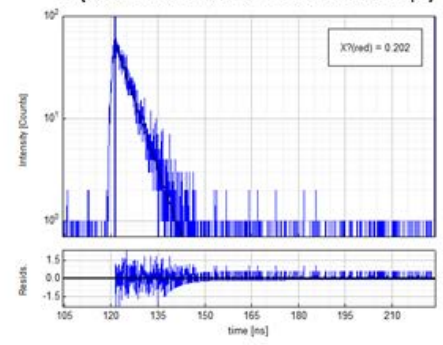

$t(i)=\sum_{-1}^{\infty} e^{-\frac{1}{4}}$

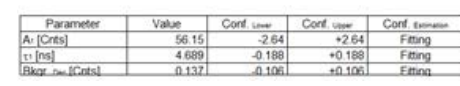

b 2

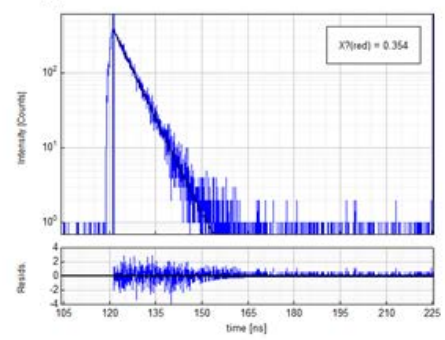

$t(0)=\sum-1 e^{-\frac{1}{2}}$
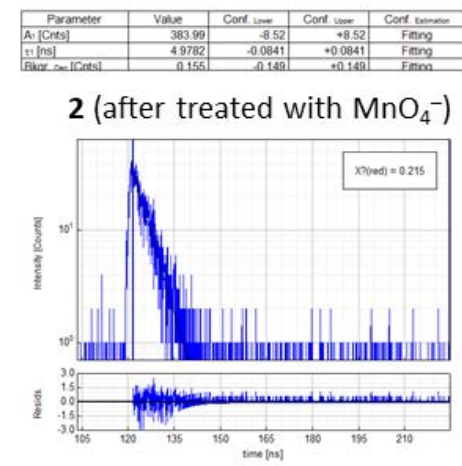

lit) $-\sum_{i=1}+e^{-i}$

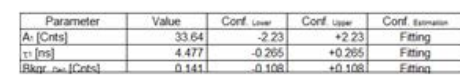

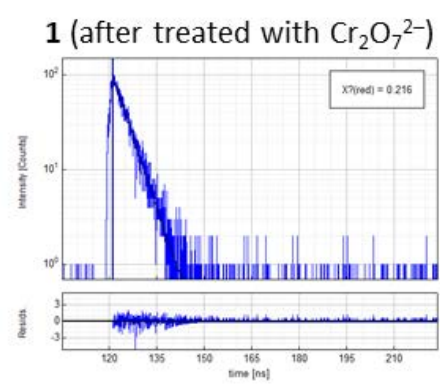

$r(1) \cdot \sum_{i=1} e^{-\frac{1}{t}}$

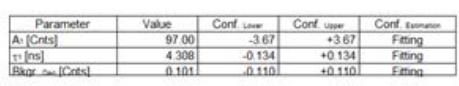

$\mathbf{1}$ (after treated with $\mathrm{Fe}^{3+}$ )

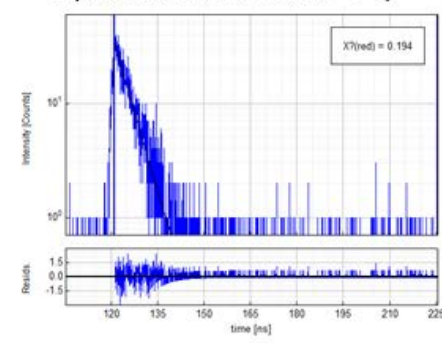

(10) $-\sum \sum_{i} e^{-\frac{4}{4}}$

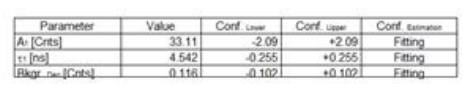

2 (after treated with $\mathrm{Cr}_{2} \mathrm{O}_{7}{ }^{2-}$ )

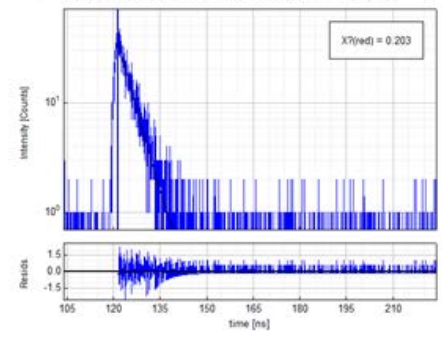

$t(i)=\sum-4 e^{-\frac{t}{t}}$

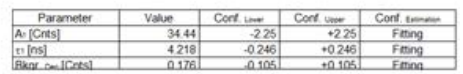

$\mathbf{2}$ (after treated with $\mathrm{Fe}^{3+}$ )

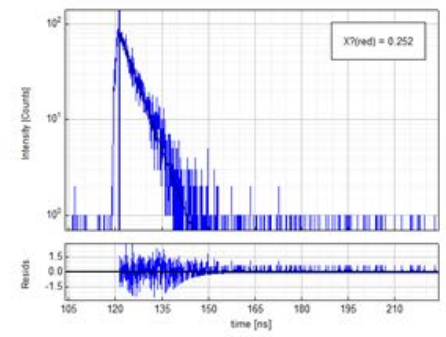

$l(\omega)=\sum_{i=1} e^{-\frac{t}{6}}$

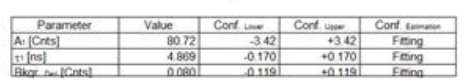

Figure S6. Fluorescence lifetime measurements for (a) 1 and (b) $\mathbf{2}$ before and after treated with $\mathrm{Cr}_{2} \mathrm{O}_{7}{ }^{2-}, \mathrm{MnO}_{4}^{-}$, and $\mathrm{Fe}^{3+}$. 
a

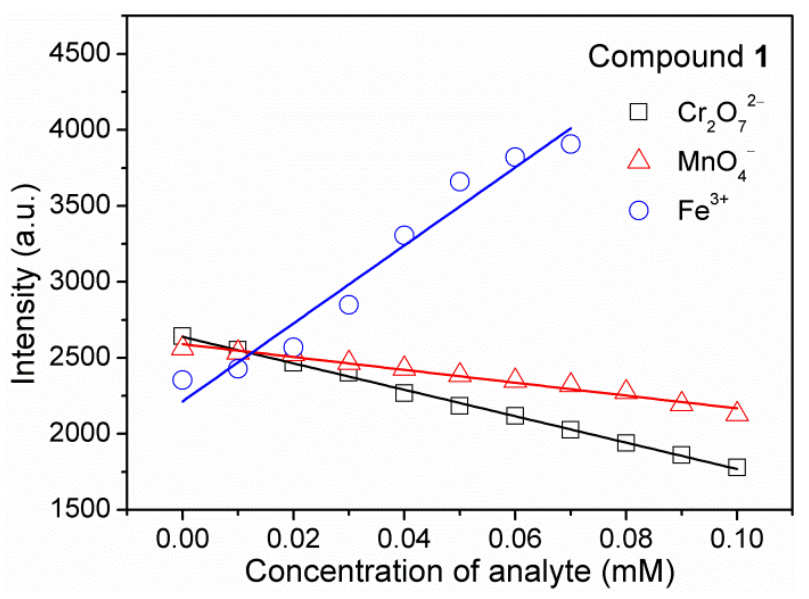

b

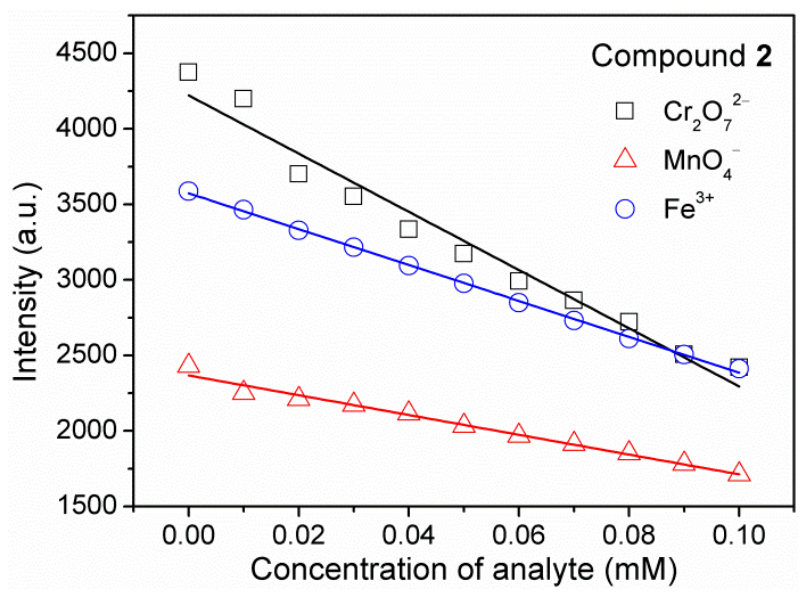

\begin{tabular}{|c|c|c|c|c|c|c|}
\hline & \multicolumn{3}{|c|}{1} & \multicolumn{3}{|c|}{2} \\
\hline & $\mathrm{Cr}_{2} \mathrm{O}_{7}^{2-}$ & $\mathrm{MnO}_{4}^{-}$ & $\mathrm{Fe}^{3+}$ & $\mathrm{Cr}_{2} \mathrm{O}_{7}^{2-}$ & $\mathrm{MnO}_{4}^{-}$ & $\mathrm{Fe}^{3+}$ \\
\hline Blank reading 1 & 2642 & 2564 & 2350 & 4370 & 2424 & 3583 \\
\hline Blank reading 2 & 2653 & 2561 & 2353 & 4365 & 2423 & 3597 \\
\hline Blank reading 3 & 2634 & 2562 & 2354 & 4364 & 2427 & 3585 \\
\hline Blank reading 4 & 2646 & 2565 & 2353 & 4372 & 2427 & 3589 \\
\hline Blank reading 5 & 2642 & 2563 & 2359 & 4375 & 2431 & 3588 \\
\hline Standard deviation $(\sigma)$ & 6.914 & 1.581 & 3.271 & 4.658 & 3.130 & 5.367 \\
\hline |Slope | (k), $\mathrm{mM}^{-1}$ & 8699 & 4230 & 25670 & 19271 & 6551 & 11889 \\
\hline$R^{2}$ & 0.99777 & 0.97585 & 0.95502 & 0.96739 & 0.98249 & 0.99892 \\
\hline $\operatorname{LOD}(3 \sigma / k), \mu \mathrm{M}$ & 2.38 & 1.12 & 0.382 & 0.725 & 1.43 & 1.35 \\
\hline
\end{tabular}

Figure S7. Linear region of fluorescence intensity for (a) $\mathbf{1}$ and (b) $\mathbf{2}$ dispersed in DMF upon incremental addition of $\mathrm{Cr}_{2} \mathrm{O}_{7}{ }^{2-}, \mathrm{MnO}_{4}{ }^{-}$, and $\mathrm{Fe}^{3+}$. Conditions: $\lambda_{\mathrm{ex}}=360 \mathrm{~nm}$ for $\mathbf{1}$ and 2. The following table lists the relevant parameters of LOD of 1 and $\mathbf{2}$ suspensions in DMF solvent toward $\mathrm{Cr}_{2} \mathrm{O}_{7}{ }^{2-}, \mathrm{MnO}_{4}{ }^{-}$, and $\mathrm{Fe}^{3+}$. 
Table S1. $K_{\text {sv }}$ values and LODs for the reported CP-based fluorescence sensors for $\mathrm{Cr}_{2} \mathrm{O}_{7}{ }^{2-}, \mathrm{MnO}_{4}{ }^{-}$, and Fe ${ }^{3+}$ sensing in DMF

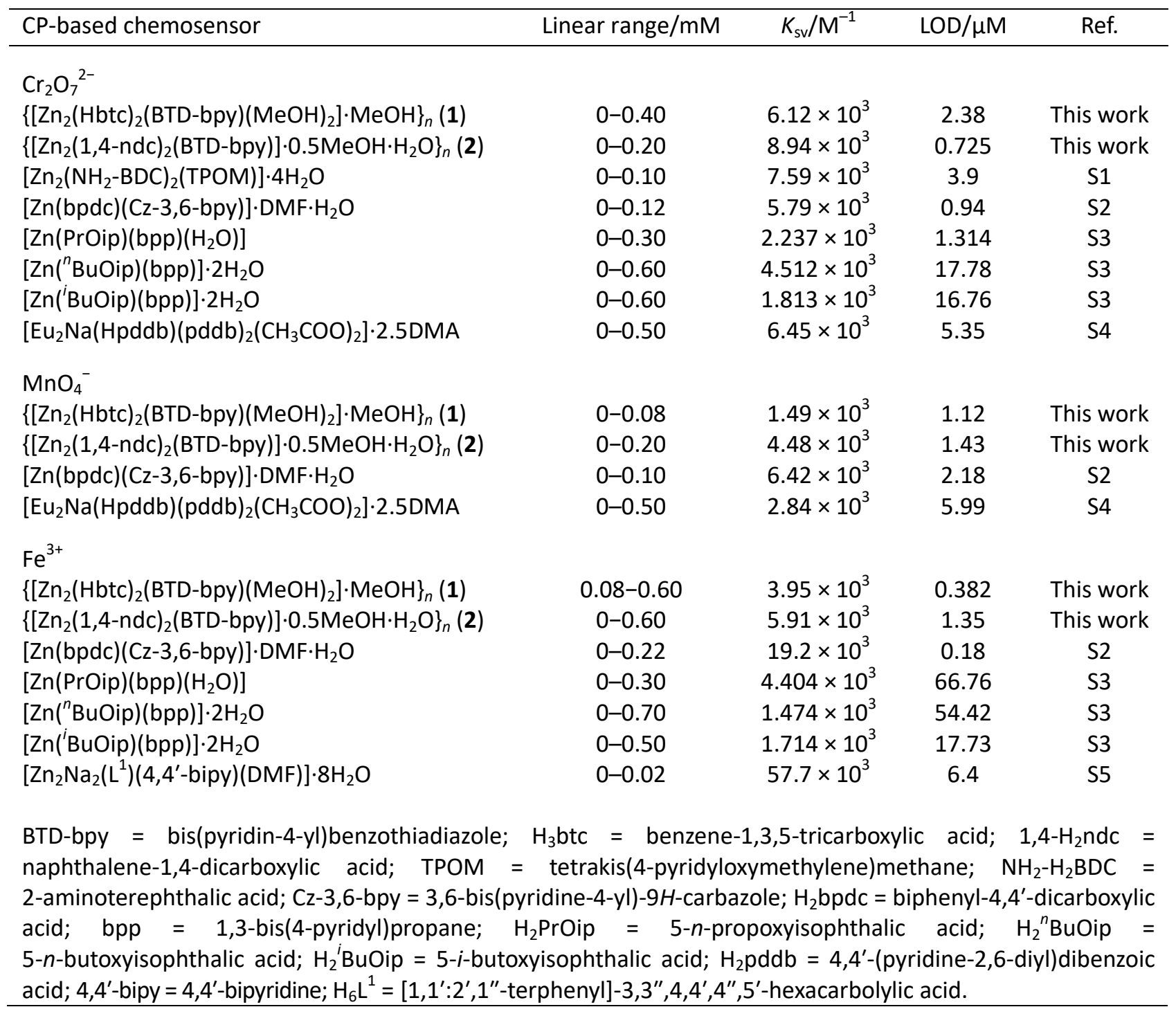

\section{References}

S1 Lv, R.; Wang, J.; Zhang, Y.; Li, H.; Yang, L.; Liao, S.; Gu, W.; Liu, X. An amino-decorated dual-functional metal-organic framework for highly selective sensing of $\mathrm{Cr}(\mathrm{III})$ and $\mathrm{Cr}(\mathrm{VI})$ ions and detection of nitroaromatic explosives, J. Mater. Chem. A 2016, 4, 15494-15500.

S2 Huang, Y.-W.; Chuang, P.-M.; Wu, J.-Y. Solvent-Induced Controllable Supramolecular Isomerism: Phase Transformation, $\mathrm{CO}_{2}$ Adsorption, and Fluorescence Sensing toward $\mathrm{CrO}_{4}{ }^{2-}, \mathrm{Cr}_{2} \mathrm{O}_{7}{ }^{2-}, \mathrm{MnO}_{4}{ }^{-}$and $\mathrm{Fe}^{3+}$. Inorg. Chem. 2020, 59, 9095-9107.

S3 Zhu, R.-R.; Wang, T.; Wang, D.-W.; Yan, T.; Wang, Q.; Li, H.-X.; Xue, Z.; Zhou, J.; Du, L.; Zhao, Q.-H. Zinc-based CPs for effective detection of $\mathrm{Fe}^{3+}$ and $\mathrm{Cr}_{2} \mathrm{O}_{7}{ }^{2-}$ ions, New. J. Chem. 2019, 43, 1494-1504.

S4 Xu, S.; Shi, J.-J.; Ding, B.; Liu, Z.-Y.; Wang, X.-G.; Zhao, X.-J.; Yang, E.-C. A heterometallic sodium(I)-europium(III)-organic layer exhibiting dual-responsive luminescent sensing for nitrofuran antibiotics, $\mathrm{Cr}_{2} \mathrm{O}_{7}{ }^{2-}$ and $\mathrm{MnO}_{4}{ }^{-}$anions, Dalton Trans. 2019, 48, 1823-1834.

S5 Yu, C.; Sun, X.; Zou, L.; Li, G.; Zhang, L.; Liu, Y. A Pillar-Layered Zn-LMOF with Uncoordinated Carboxylic Acid Sites: High Performance for Luminescence Sensing Fe ${ }^{3+}$ and TNP, Inorg. Chem. 2019, 58, 4026-4032. 

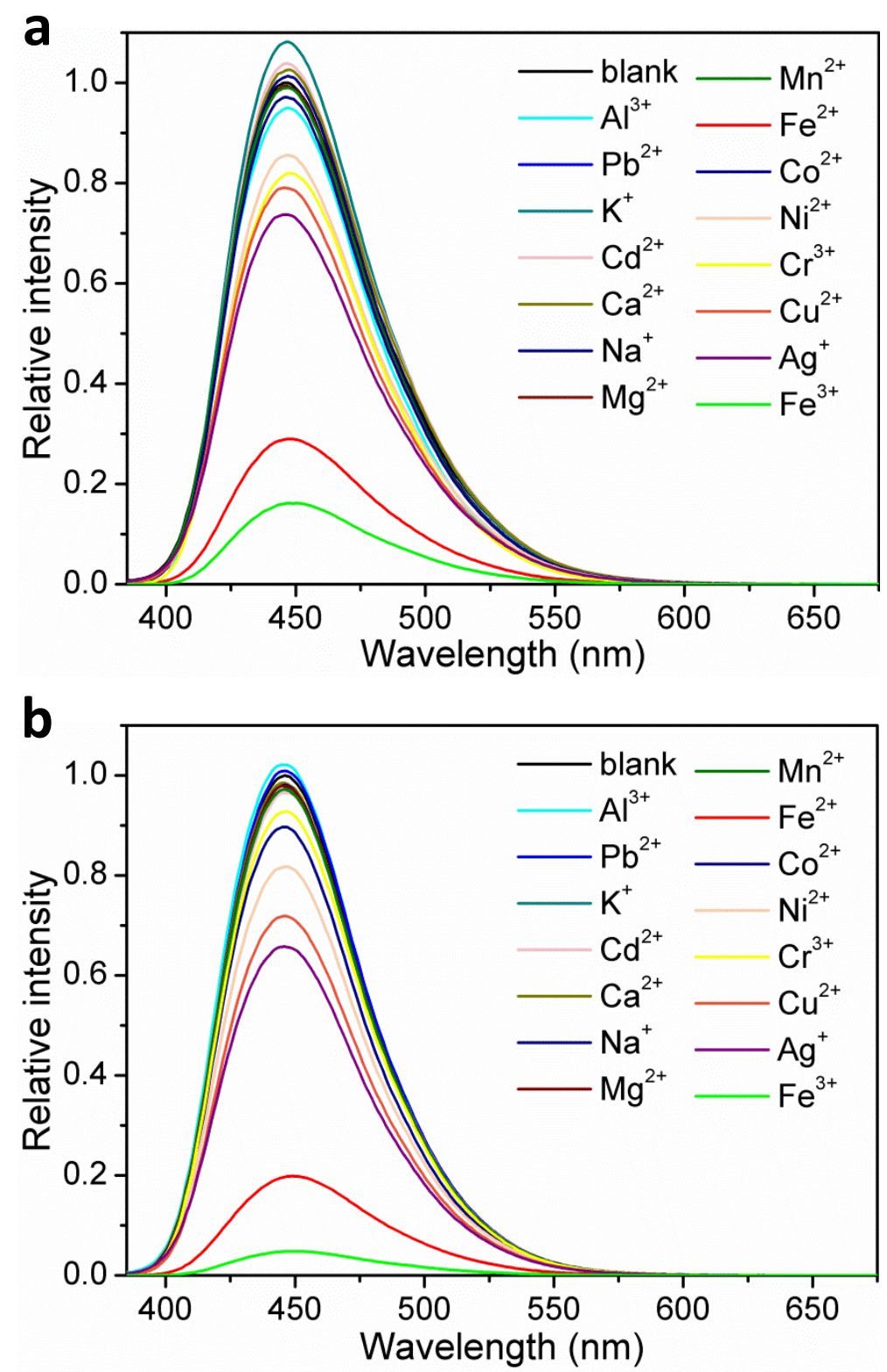

Figure S8. Emission spectra of (a) 1 and (b) $\mathbf{2}$ dispersed in DMF solvent upon addition of different metal ions at room temperature when excited at $360 \mathrm{~nm}$. 
a
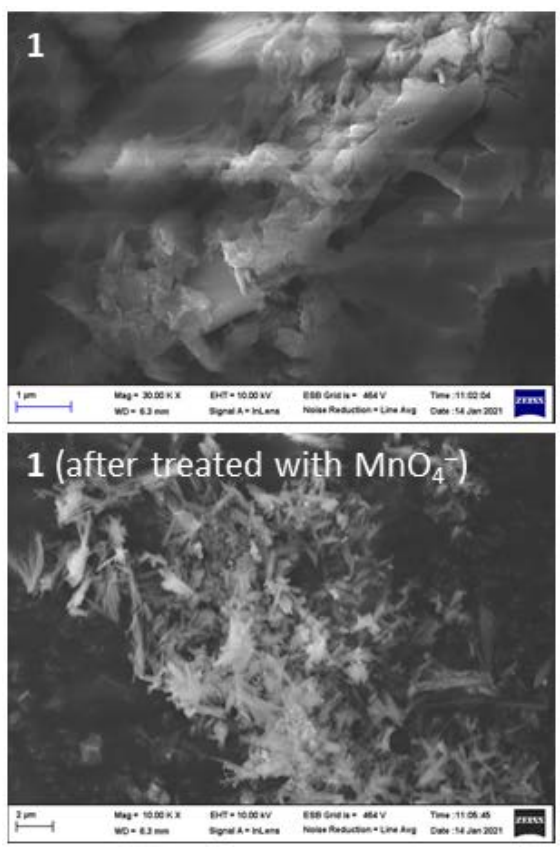

b
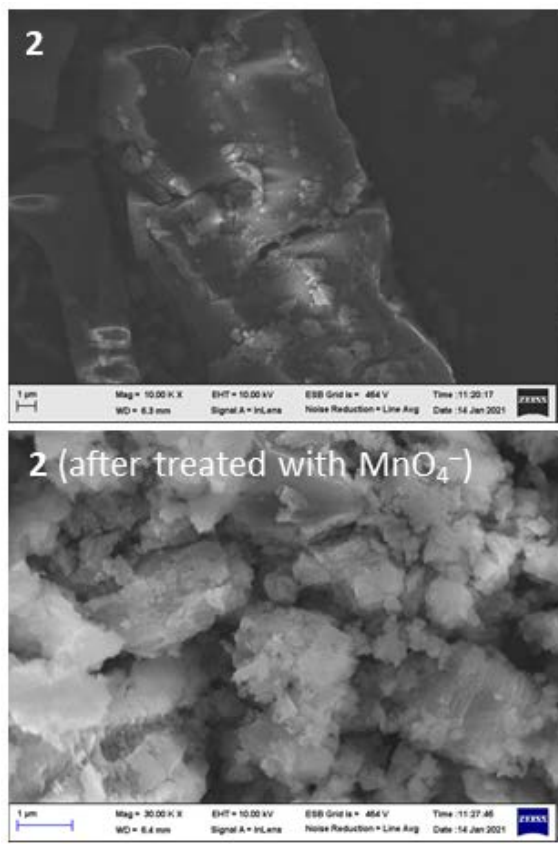
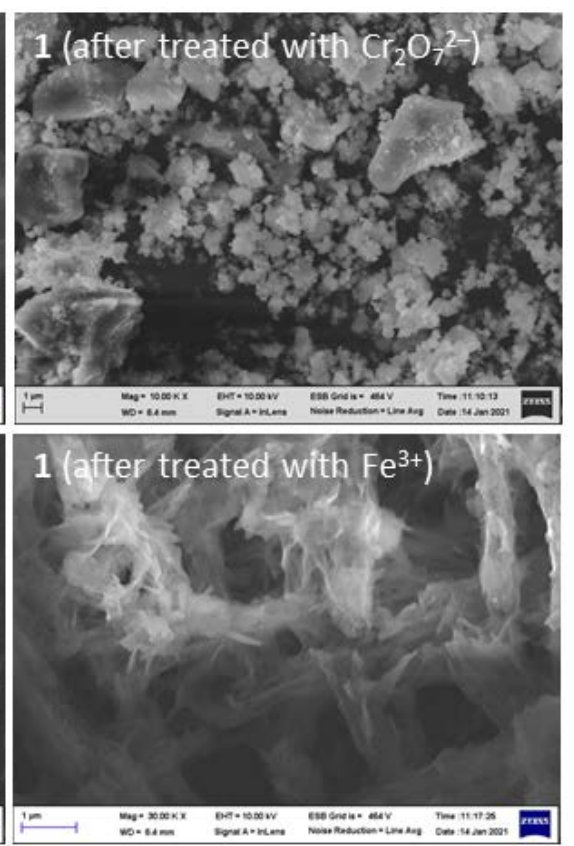

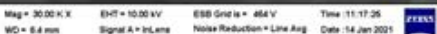
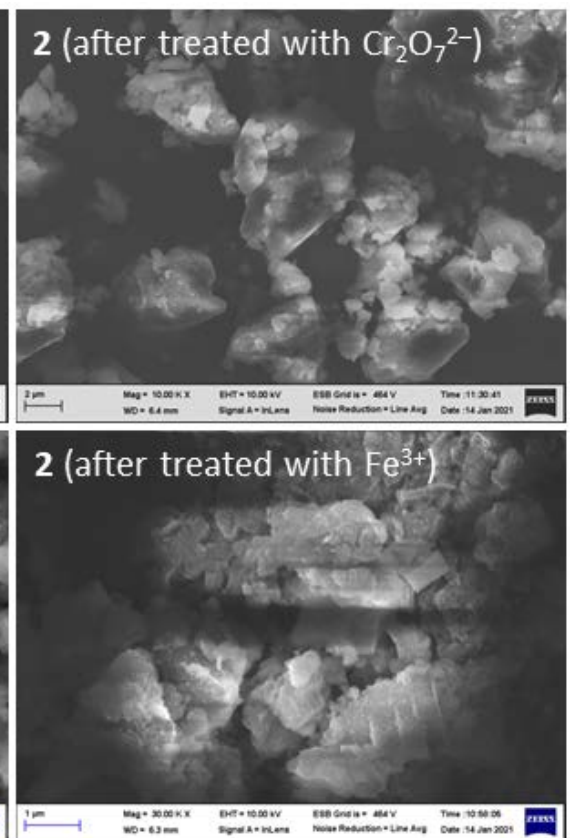

Figure S9. SEM micrographs of (a) 1 and (b) 2 before and after treated with $\mathrm{Cr}_{2} \mathrm{O}_{7}{ }^{2-}, \mathrm{MnO}_{4}{ }^{-}$, and $\mathrm{Fe}^{3+}$. 
a
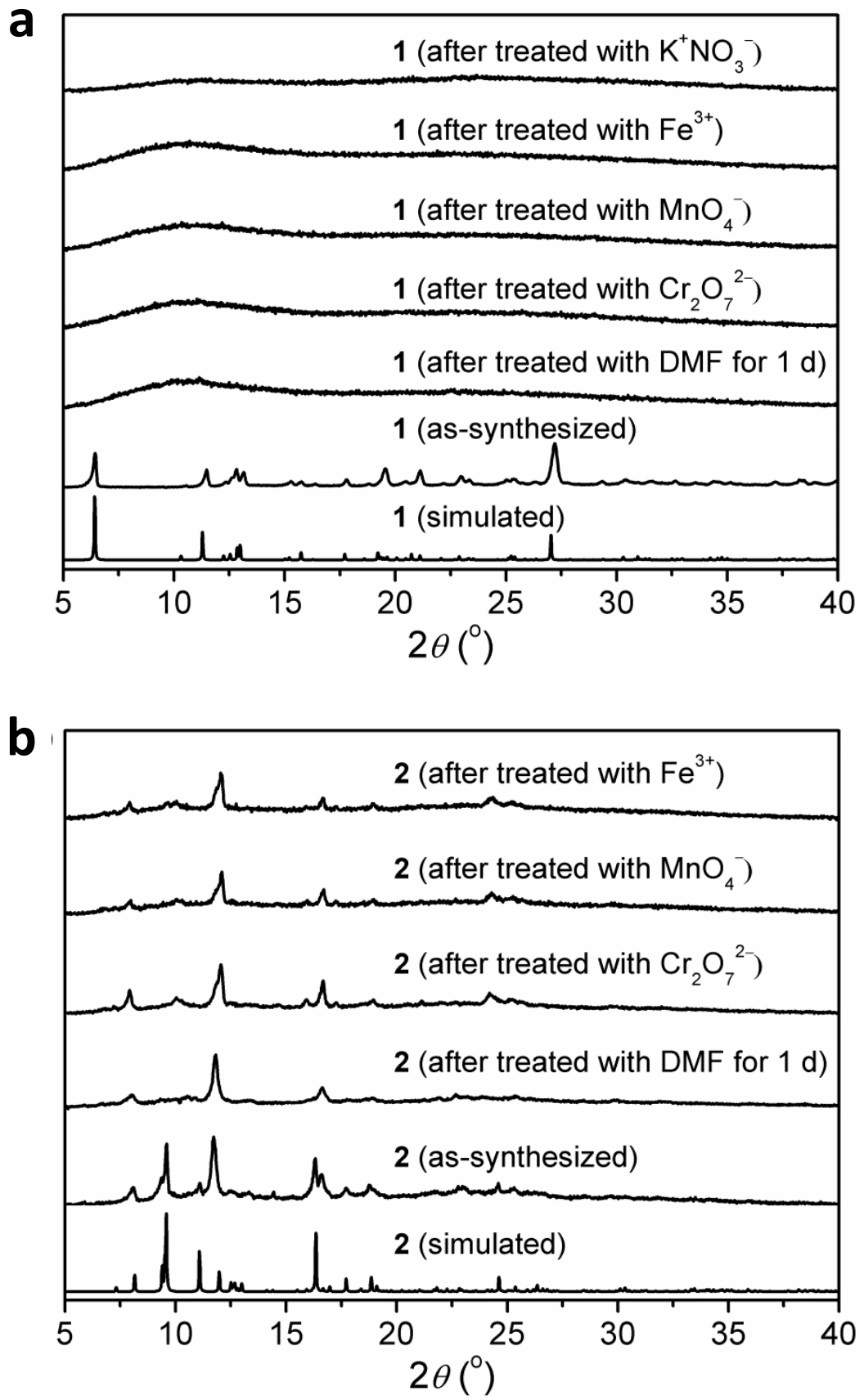

Figure S10. XRPD patterns of (a) 1 and (b) $\mathbf{2}$ in different situations. 


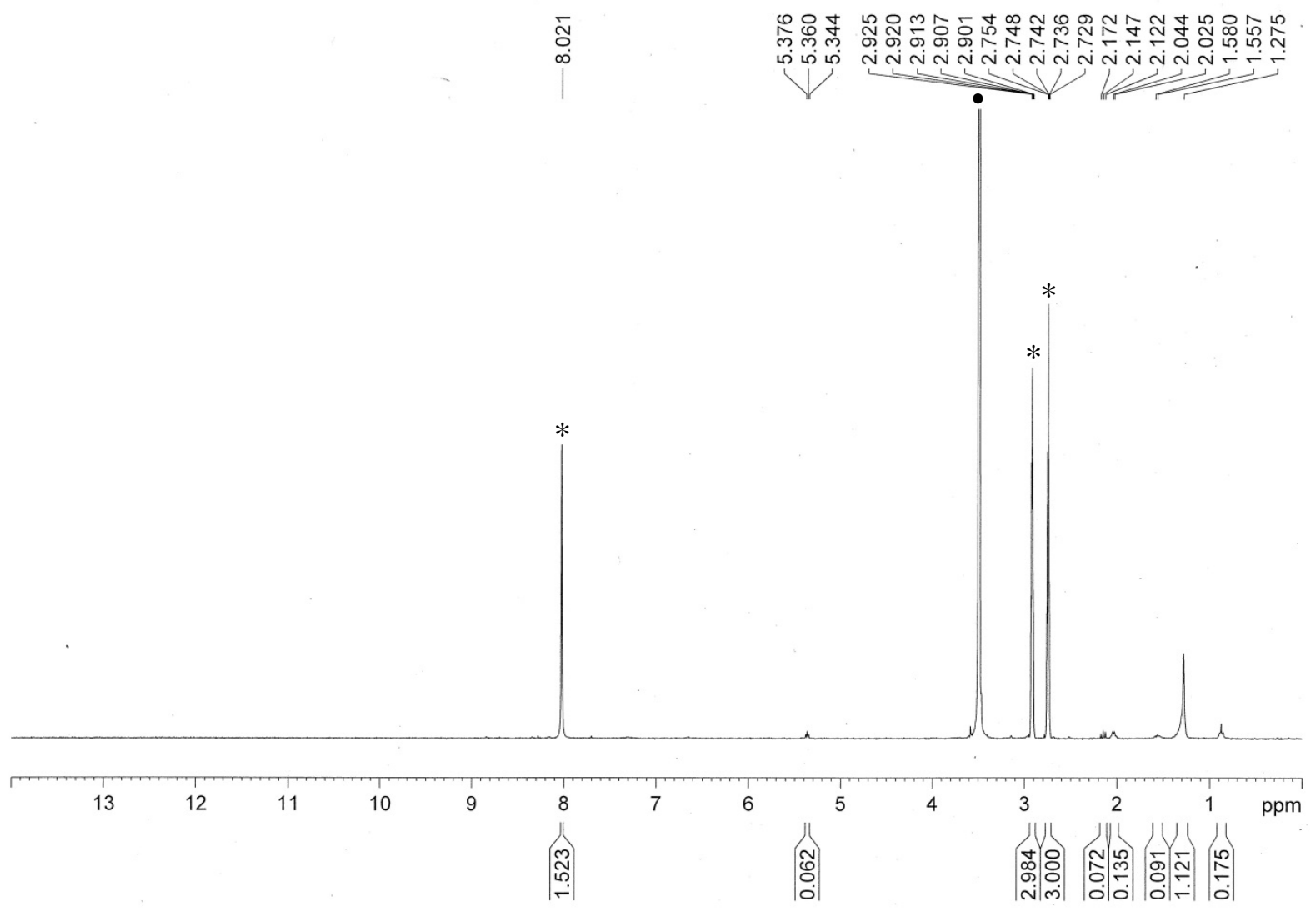

Figure S11. ${ }^{1} \mathrm{H}$ NMR spectrum of 1 after immersing in DMF- $d_{7}$ for 1 day. Asterisk symbols represent the signals originated from DMF solvent, whereas solid circle symbol represents the signal originated from $\mathrm{H}_{2} \mathrm{O}$.

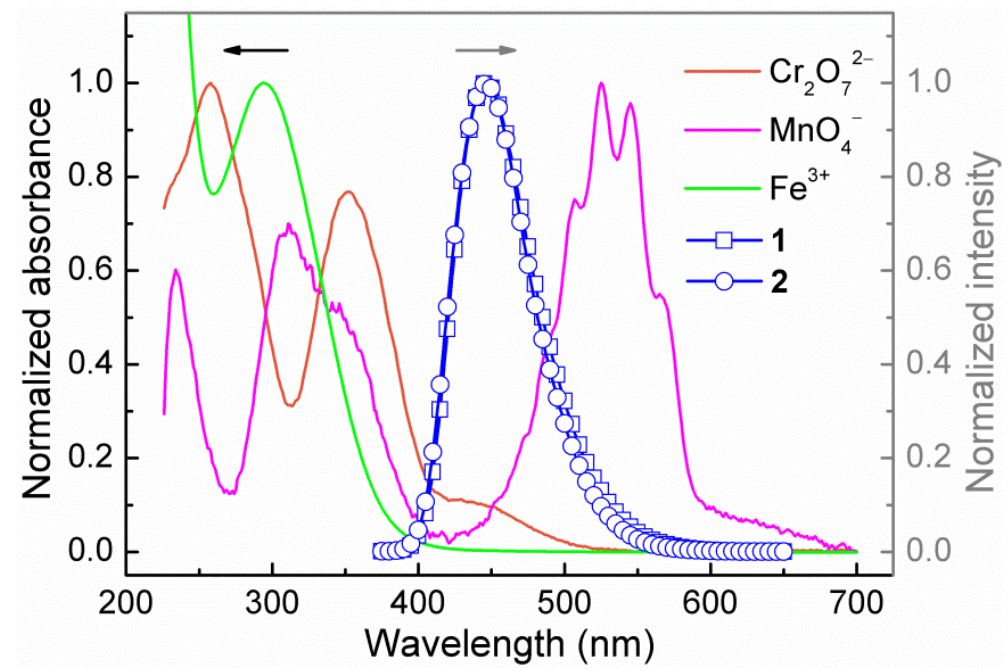

Figure S12. Spectral overlapping between the normalized absorption spectra of $\mathrm{Cr}_{2} \mathrm{O}_{7}{ }^{2-}, \mathrm{MnO}_{4}{ }^{-}$, and $\mathrm{Fe}^{3+}$ in aqueous solutions and the normalized emission spectra of $\mathbf{1}$ and $\mathbf{2}$ dispersed in DMF solvent. 

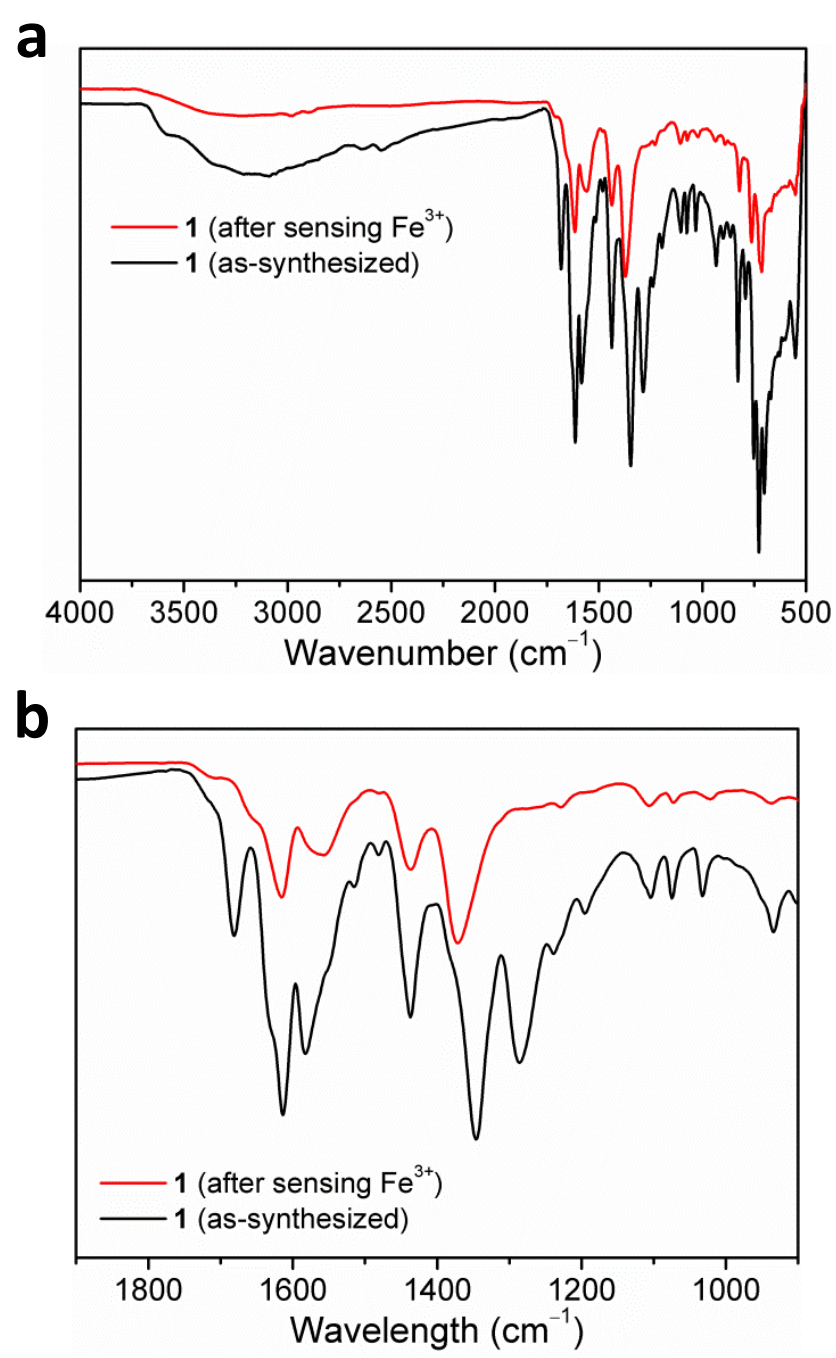

Figure S13. (a) Overlapping the IR spectra of 1 before and after sensing $\mathrm{Fe}^{3+}$. (b) Highlight the IR spectra in the $1900-900 \mathrm{~cm}^{-1}$ region of 1 in (a). 

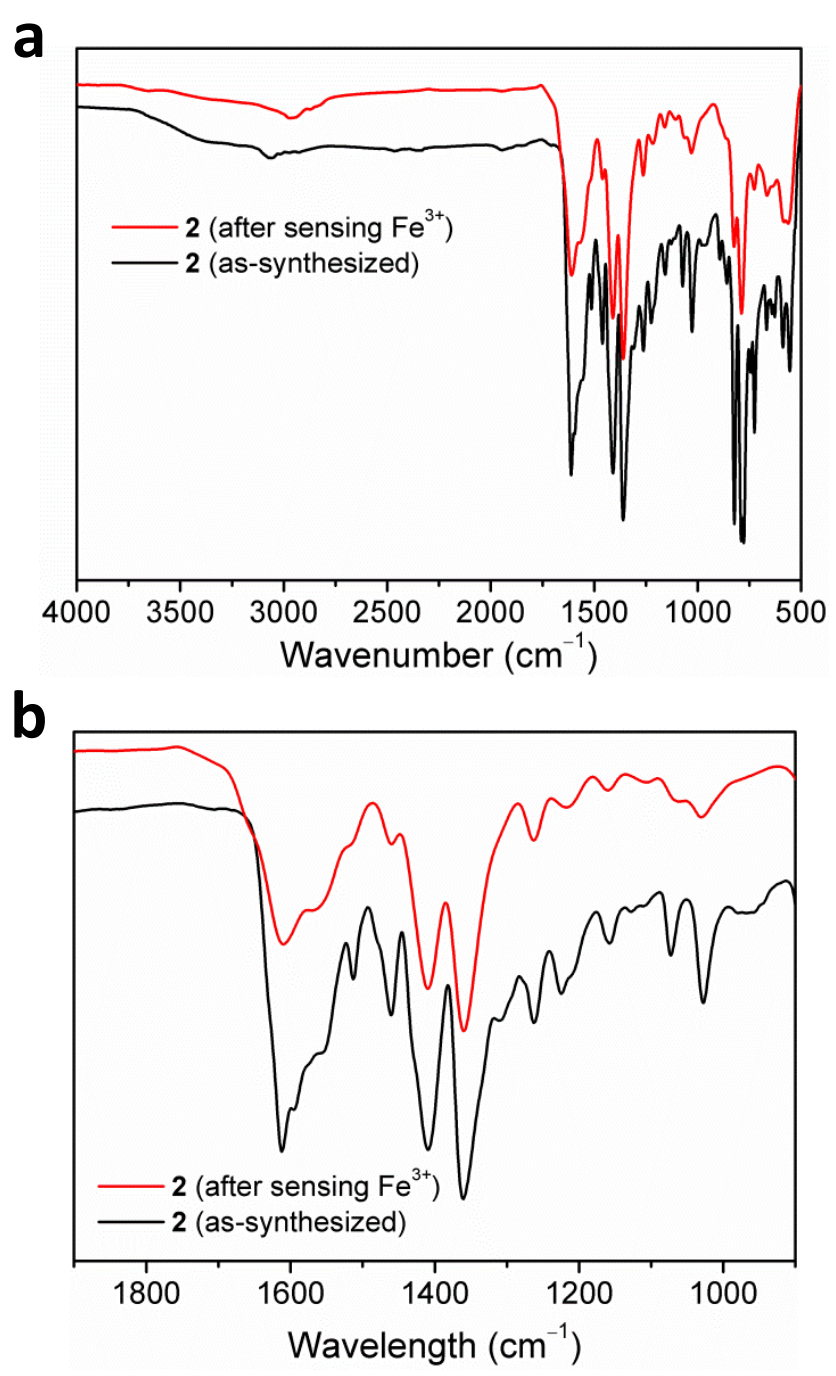

Figure S14. (a) Overlapping the IR spectra of 2 before and after sensing $\mathrm{Fe}^{3+}$. (b) Highlight the IR spectra in the $1900-900 \mathrm{~cm}^{-1}$ region of 2 in (a). 